\title{
Procedimentos de contagem de pontos em um jogo com conteúdo matemático
}

\author{
Cláudia Patrocinio Pedroza Canal \\ Sávio Silveira de Queiroz
}

\begin{abstract}
Resumo
Os alunos apresentam grandes dificuldades na matemática, particularmente no conteúdo dos números inteiros. Diversos trabalhos demonstram como jogos auxiliam na construção de conhecimentos. Assim, esta pesquisa verificou, por meio de um jogo com números inteiros, procedimentos utilizados para realizar as operações de contagem de pontos. Participaram 34 alunos dos $7^{\circ}$ e $9^{\circ}$ anos do Ensino Fundamental, que jogaram duas rodadas de três partidas contra oponentes de mesma série que a sua. Classificaram-se os dados em a) procedimentos de contagem de pontos e b) contagem correta e incorreta. Os resultados mostraram associação entre os procedimentos mais simples e o $7^{\circ}$ ano e os mais complexos com o $9^{\circ}$ ano. Entretanto, os participantes contaram incorretamente os pontos na maioria das partidas. Assim, apesar da associação entre maior nível de escolarização e estratégias mais complexas, estas não determinaram a contagem correta no jogo, demonstrando dificuldade na realização e na compreensão das operações avaliadas.
\end{abstract}

Palavras-chave: Jogos, ensino da matemática, ensino fundamental.

\section{Counting points in a game with mathematical content: some procedures}

\begin{abstract}
Students may have great difficulties in mathematics, particularly in the content of integers. Several studies demonstrate how games help in building knowledge. In this work we explore procedures used to perform the operations of counting points in a game. 34 students from the 7 th and 9th years of elementary school took part of the research. They played two rounds of three games against opponents from the same grade. The data were classified into a) point-counting procedures and b) correct and incorrect counting. The results show an association between the simpler procedures with the 7th year and more complex procedures with the 9th grade. However, participants told incorrectly points in most games. Thus, despite the association between higher educational level and more complex strategies, they have not determined the correct count in the game. This reveals the difficulty in performing and understanding of the operations evaluated.
\end{abstract}

Keywords: Games, mathematics education, elementary education.

\section{Procedimientos de conteo de puntos en juego con contenido matemático}

\section{Resumen}

Los alumnos presentan grandes dificultades en matemática, particularmente en el contenido de números enteros. Diversos trabajos demuestran como juegos auxilian en la construcción de conocimientos. Así, esta investigación verificó, por medio de un juego con números enteros, procedimientos utilizados para realizar las operaciones de conteo de puntos. Participaron 34 alumnos del $7^{\circ}$ y $9^{\circ}$ grados de Enseñanza Primaria, que jugaron dos rondas de tres partidos contra oponentes del mismo grado que el suyo. Los datos se clasificaron en a) procedimientos de conteo de puntos y b) conteo correcto e incorrecto. Los resultados mostraron asociación entre los procedimientos más simples y el $7^{\circ}$ grado y los más complejos con el $9^{\circ}$ grado. No obstante, los participantes contaron incorrectamente los puntos en la mayoría de los partidos. Así, a pesar de la asociación entre mayor nivel de escolarización y estrategias más complejas, estas no determinaron el conteo correcto en el juego, demostrando dificultad en realizar y comprender las operaciones evaluadas.

Palabras Clave: Juegos, Enseñanza de las matemáticas, Enseñanza Primaria. 


\section{Introdução}

A matemática é uma das disciplinas em que os alunos demonstram particular dificuldade na escola, como nos mostra Klein (2006) ao interpretar resultados do Sistema Nacional de Avaliação da Educação Básica brasileiro, no ano de 2003, em relação a essa área do conhecimento. Conforme classificação desse autor, no $4^{\circ}$ ano do Ensino Fundamental, 48,4\% dos alunos encontravam-se distribuídos a partir do que considera o nível básico de saber nessa disciplina e apenas $6,4 \%$ a partir do nível satisfatório; no $9^{\circ}$ ano, 26,3\% a partir do básico e 3,3\% do satisfatório; e no $3^{\circ}$ ano do Ensino Médio, 6,9\% a partir do básico e 1,3\% do satisfatório. Esses dados são realmente alarmantes para a educação brasileira.

Nessa área acadêmica, a compreensão dos números inteiros, conjunto que envolve os números naturais e inclui os números negativos, que deveria estabelecer-se, satisfatoriamente, nos alunos do $9^{\circ}$ ano do Ensino Fundamental, de acordo com Klein (2006), apresenta grande dificuldade no contexto educacional brasileiro.

Os números negativos geram muitos obstáculos à compreensão dos alunos, como demonstraram algumas pesquisas (Nieto, 1994; Tancredi, 1989). Ao ensinar o conteúdo sobre números naturais, os professores geralmente fazem referência a objetos que existem no mundo real, tornando concreta para o aluno a abstração existente no conceito de número. Entretanto, esse recurso não é utilizado no ensino do número negativo, já que é impossível fazer referência à existência de quantidade de menos um objeto qualquer no mundo real.

Historicamente, na matemática, a noção de número negativo demorou vários anos para se consolidar. Tancredi (1989) relata que os chineses já mencionavam os números negativos em 200 a.C.; Boyer (2001) relata, sobre a evolução dos estudos sobre os números negativos, que no ano 300 aproximadamente os chineses usavam barras de bambu, marfim ou ferro colocadas sobre uma tábua de madeira para efetuar cálculos e contagens. Para isso, eles possuíam duas coleções de barras de cores diferentes. Uma coleção era vermelha e representava números e coeficientes positivos, enquanto a outra era preta e representava os números e coeficientes negativos. Apesar de já realizarem cálculos envolvendo números negativos, os chineses não aceitavam a ideia de um desses números representar a solução de um problema.

Entre os matemáticos hindus, Brahmagupta, por volta do ano 628, prestou grande contribuição à álgebra ao propor soluções de equações quadráticas, inclusive duas raízes, mesmo quando uma delas fosse negativa. Boyer (2001) afirma que é na obra de Brahmagupta que, pela primeira vez, encontra-se sistematizada a aritmética dos números negativos e do zero.

Em 1489, na Alemanha, Johann Widman publicou uma obra de aritmética comercial, Rechnung auff allen Kauffmanschaffen, que, de forma inédita, apresentou impressos os sinais + e - para representar os números positivos e negativos, respectivamente.

Em 1544, Michael Stifel, também alemão, publicou a obra Arithmetica integra, na qual estudou os números negativos ao analisar as equações quadráticas. Porém ainda não os aceitava como raízes de uma equação e os chamava de "numeri absurdi" (número absurdo).

Na Idade Moderna, Albert Girard, em sua obra Invention nouvelle en l'algèbre (Teorema fundamental da álgebra), foi o primeiro a admitir raízes negativas como soluções possíveis de uma equação. Ele também antecipou a ideia da reta numérica, em que há uma oposição de sentido entre os números positivos e negativos.

Nieto (1994) afirma que apenas em 1867, com Hermann Hankel, o conhecimento sobre números negativos atinge um patamar mais elaborado, pois esse autor considerou os números negativos como números inventados, ampliando o conjunto dos números inteiros para abrigar também os números negativos.

Para auxiliar o professor em sala de aula com os números negativos, que historicamente se mostraram tão difíceis de ser compreendidos, alguns trabalhos (French, 2001; Puritz, 2004) apresentam dicas, fornecendo sentido a algumas regras que são, na maioria das vezes, ensinadas de forma abstrata aos alunos, como quando, ao lecionar sobre a multiplicação e divisão dos números negativos, alguns mestres enunciam a lei "menos com menos dá mais" muitas vezes sem contextualização e significação para o aluno. Sobre isso, durante a coleta de dados do estudo-piloto dessa pesquisa, realizado em 2006 numa escola pública de ensino fundamental de Vitória, duas alunas do $9^{\circ}$ ano jogavam o Mattix, quando, ao final do jogo, foram contar seus pontos. Uma das alunas contou da seguinte forma: $[(-5)+(-2)]=+7$; afinal "Menos com menos dá mais", como aprendera em sala de aula.

Mostrando que não é suficiente a transmissão dos conteúdos didáticos sobre os números inteiros para que os alunos construam conhecimento a esse respeito, Piaget (1948/2005) defendeu que, para compreensão da regra matemática de operações com números inteiros, ensinada atualmente nos $3^{\circ}$ e $4^{\circ}$ ciclos do Ensino Fundamental, é necessário que o indivíduo a descubra bem antes em ação. Piaget (1948/2005) apontou como essencial que o professor recorra à atividade real e espontânea do aluno para que realmente consiga levá-lo à construção dos conceitos escolares. Panizza (2006) também ressaltou a necessidade de que o conhecimento escolar deve partir do que o aluno já sabe, alertando que não é tarefa fácil identificar esse saber. O conceito de "teorema em ato ou em ação" de Vergnaud é apresentado como essencial para compreensão desse saber, pois o professor deve procurar perceber o que o aluno sabe em ato para, a partir disso, buscar a construção de representações e procedimentos diferenciados na resolução de um problema (Panizza, 2006).

Vergnaud (1990), no artigo sobre a Teoria dos Campos Conceituais, abordou uma série de aspectos em relação ao conhecimento matemático. O autor defendeu que 
um conceito recebe sentido por meio das situações e dos problemas que se pretende resolver. Assim, para a didática essa constatação é fundamental.

Vergnaud (1990) utiliza como exemplo o algoritmo de resolução de adição com números inteiros. Os professores ensinam o alinhamento dos números a serem somados, o início pela coluna das unidades, a regra de, se soma tiver como resultado número maior que 9 , a unidade deve ser transcrita e a dezena adicionada à coluna seguinte. Entretanto, quando essas regras não fazem sentido, não comparecem em ação, os alunos podem não ter o desempenho apropriado na resolução de problemas desse tipo.

O funcionamento cognitivo do sujeito fundamenta-se em um repertório de esquemas disponíveis, já formados. Durante a resolução de problemas, a pessoa reconhece novos aspectos e até mesmo constrói novos esquemas.

Vergnaud (1990) defendeu que a operacionalidade de um conceito deveria ser experimentada em situações variadas. A Teoria dos Campos Conceituais desse autor apóia-se sobre o fundamento de elaboração prática dos conceitos.

Assim, o jogo aparece como instrumento útil para intervenção no contexto escolar, ao permitir, sob a perspectiva do aluno, um ambiente mais livre em que seja possível a emergência da atividade real e espontânea, ou do saber em ato.

Fisher (2003, 2004) propôs quatro jogos para ensino na escola de números negativos e suas operações: Truncate, Race Track II, Negative Number Tennis e Boxes. O autor assinala que os jogos são ferramentas capazes de auxiliar o ensino do conteúdo, mas não substituem a orientação do professor. Para ele, a importância dos jogos reside no fato de estes permitirem que o conteúdo seja transmitido de forma mais divertida e mais atrativa e, por isso, tornem-se úteis na consolidação do conteúdo.

Fainguelernt e Gottlieb (2001) apresentaram sua experiência na utilização de jogos como metodologia no ensino-aprendizagem de Matemática, fundamentada em pesquisas realizadas no Laboratório de Currículos da Secretaria Estadual de Educação do Rio de Janeiro, nas quais utilizaram jogos para introduzir o conteúdo de números inteiros a alunos de $6^{\circ}$ ano. Em uma situação relatada no artigo, os alunos deveriam fazer encenação sobre um problema relacionado ao movimento de um estacionamento de carros. Os alunos eram solicitados a registrar a entrada e saída de carros e a diferença entre elas em intervalos de uma hora, sendo que em alguns desses intervalos essa diferença era negativa. No único resultado apresentado no artigo, o aluno, mesmo sendo do $6^{\circ}$ ano, conseguiu fazer a notação de números negativos (sinal de menos "-" antecedendo o número), mesmo sem ter tido esse conteúdo formalizado na escola.

Fainguelernt e Gottlieb (2001) alertam, porém, sobre o perigo de o professor treinar os alunos por meio de um jogo. Concordamos com essa ideia, pois consideramos importante que o professor permita que o aluno jogue, construa estratégias, vivencie dificuldades, perca, ganhe, ao invés de, como muitos o fazem, ensinar o aluno a melhor forma de jogar por meio das estratégias mais eficazes, impedindo assim que o indivíduo seja ativo na construção de seu conhecimento sobre um determinado jogo. Essa última, a nosso ver, seria uma forma de emprego de jogos que não favoreceria o processo de construção de conhecimento, já que elimina um de seus fatores necessários: o papel ativo do sujeito. Portanto, não é qualquer utilização do jogo que o torna instrumento promotor do processo de conhecimento.

Ao dizermos sujeito ativo, é necessário resgatar o sentido de ação. De acordo com Piaget, ação não é sinônimo de atividade. Como ação, esse autor também compreende processos de pensamento. Piaget (1967/1996) afirmou que todo conhecimento está relacionado a uma ação e que conhecer supõe assimilação a esquemas de ação. Os esquemas de ação são o que existe de comum nas diversas aplicações de uma mesma ação. Dessa forma, em relação ao conhecimento na área da matemática, a dedução dos fenômenos ocorreria por operações e transformações, "que são ainda ações, mas executadas mentalmente" (Piaget, 1967/1996, p. 15). Assim, quando esse autor caracteriza as formas típicas de conhecer o mundo nos diferentes momentos de desenvolvimento, afirma que inicialmente essa forma é a ação, em seguida, a ação interiorizada (ou representação) e, por último, a composição de ações, sendo essas possíveis de serem invertidas (ou operação) (Piaget, 1964/2004). Assim, ao dizermos que a utilização do jogo deve favorecer o papel ativo do sujeito, nossa discussão se situa nesse referencial sobre ação, considerando, portanto, o jogo possibilidade de desenvolvimento.

Buscando, portanto, compreender o papel de um jogo matemático - o Mattix - como auxiliar na construção do conhecimento sobre realização de operações algébricas com números inteiros, a pesquisa relatada neste artigo teve como objetivo avaliar e comparar os procedimentos utilizados por alunos de $7^{\circ}$ e $9^{\circ}$ anos do Ensino Fundamental para realizar operações aritméticas com números inteiros na contagem de pontos ao final do jogo.

\section{Aspectos Metodológicos}

\section{Participantes}

Participaram 34 alunos (18 meninos e 16 meninas) dos $7^{\circ}$ (16 alunos) e $9^{\circ}$ (18 alunos) anos do Terceiro e Quarto Ciclos do Ensino Fundamental, de uma escola pública da Grande Vitória-ES, dos turnos matutino e vespertino.

Esses alunos se dispuseram voluntariamente a participar dos procedimentos da pesquisa, após apresentação da mesma em reunião de pais e alunos. Após o consentimento fornecido por seus responsáveis, iniciaram sua participação na pesquisa.

As séries foram escolhidas tendo por base o texto dos Parâmetros Curriculares Nacionais para Matemática (Ministério da Educação/ Secretaria de Educação Fundamental, 1998), segundo o qual o conteúdo de números negativos, 
presente no jogo Mattix, é introduzido na escola por volta do $7^{\circ}$ ano. Marangon (2004), ao escrever sobre possibilidades de uso do jogo Mattix por professores como ferramenta de ensino, também indica que ele seja jogado com alunos de turmas de $7^{\circ}$ ano. Assim, procuramos comparar o desempenho de alunos do $7^{\circ}$ ano, que estavam aprendendo 0 conteúdo "números negativos", com alunos do $9^{\circ}$ ano, que, presumidamente, já realizavam operações mais complexas com esse conteúdo.

\section{Instrumento}

Jogo Mattix. De acordo com Dal Monte (2006), esse jogo foi editado na década de 1970 pela empresa alemã "Berliner Spiele".

O Mattix é um jogo de tabuleiro jogado por duas pessoas, apresentado sob a forma de uma matriz quadrada, composta por peças com números positivos e negativos e por uma peça curinga, que pode se movimentar durante o jogo.

A versão utilizada na pesquisa aqui relatada, idêntica à originalmente editada, é composta por um tabuleiro, dividido em 8 linhas e 8 colunas, e por 64 peças assim distribuídas: 30 peças de valor $0,1,2,3,4,5$, sendo cinco peças de cada um desses valores; seis peças de valor 6; nove peças de valor $7,8,10$, sendo três peças de cada valor; uma peça de valor $15 ; 15$ peças de valor $-1,-2,-3,-4,-5$, sendo três de cada valor; duas peças de valor -10 e uma peça curinga.

Segundo a determinação inicial, a primeira pessoa joga no sentido horizontal e, a segunda, no vertical. Inicialmente, as peças são dispostas aleatoriamente no tabuleiro. Durante o jogo, o participante movimenta a peça curinga, no sentido em que pode jogar, até a casa que possui a peça cujo número ele deseja obter para si, e esta é retirada do jogo. $\mathrm{O}$ jogo termina quando não houver mais peças no tabuleiro, ou

Figura 1. Foto da versão artesanal do jogo Mattix utilizada nessa pesquisa_

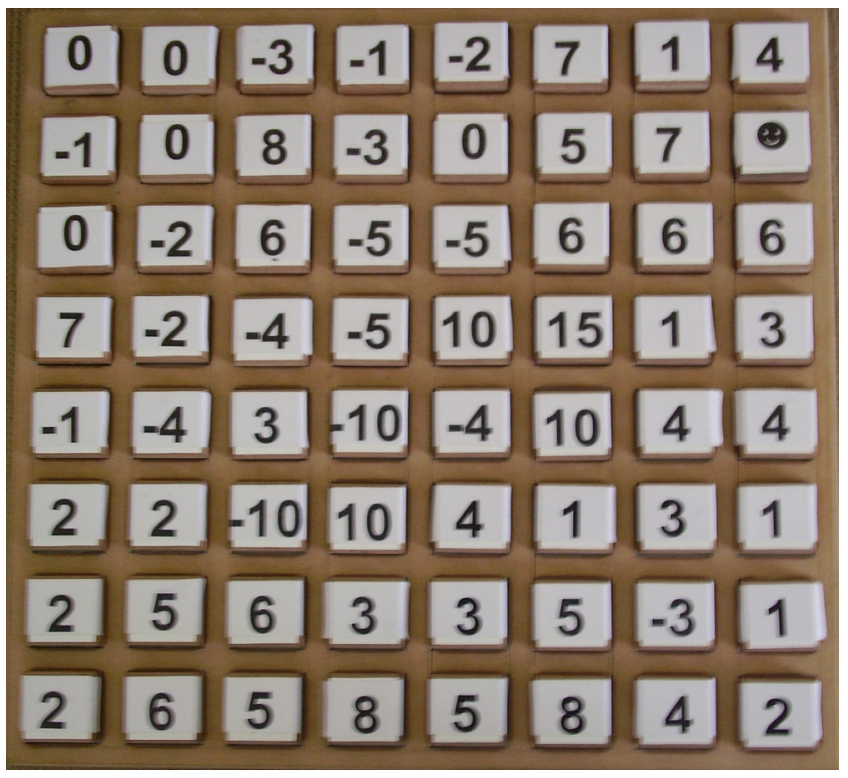

quando a peça curinga cair numa linha ou coluna sem peças a serem retiradas pelo próximo jogador. O objetivo do jogo é totalizar o maior número de pontos ao final da partida, por meio da soma algébrica das peças obtidas.

\section{Local}

Os dados foram coletados numa escola pública de ensino fundamental da Grande Vitória. Essa escola é considerada uma das escolas-modelo da rede municipal e é frequentada por pessoas de diferentes classes econômicas, que buscam ali um ensino de qualidade. Nos resultados da avaliação 2007 da Prova Brasil (Instituto Nacional de Estudos e Pesquisas Educacionais Anísio Teixeira, 2008), essa escola encontrou-se numa posição de destaque no grupo das escolas da rede pública estadual e municipal brasileiras.

\section{Procedimentos de pesquisa}

No primeiro dia, a pesquisadora apresentou o jogo aos participantes visando promover o reconhecimento do tabuleiro, das regras e dos objetivos.

Não foi esclarecido aos participantes o significado das peças negativas, já que, na análise de dados, também foi avaliada a compreensão dos alunos sobre o que representavam os números positivos e negativos.

Ainda no primeiro dia os participantes jogaram três partidas contra um adversário de mesma série e turma, filmadas para posterior análise de desempenho. As duplas de jogadores foram escolhidas por sorteio. No final da partida, durante a contagem de pontos, só foram oferecidos lápis e papel como recurso auxiliar quando solicitados pelos alunos. Após o final dessa contagem, em cada partida, o resultado que o jogador verbalizava ter obtido em pontos era anotado, assim como o seu procedimento de contagem.

No segundo dia, os participantes jogaram mais três partidas contra outro adversário de mesma série e turma. Os procedimentos foram idênticos aos do primeiro dia.

\section{Análise dos dados}

Foram originadas, após a coleta de dados, 102 partidas para análise. Em cada partida, foram analisados para cada jogador: a) os níveis do procedimento de contagem de pontos empregados; b) o resultado de pontos que obteve na partida; c) se contou corretamente os pontos obtidos.

Os níveis de procedimentos de contagem de pontos utilizados para essa análise foram criados posteriormente à coleta de dados, baseando-se nas ações de cada participante. Eles encontram-se descritos a seguir.

\section{Nível IA}

1. Não conta seus pontos ao final da partida, deixando que o adversário faça isso por ele ou inventando um resultado. 
Nível IB

1. Ao final da partida, soma todos os números como se fossem positivos.

Nível IIA

1. Mesmo que não conte seus pontos durante a partida, consegue inferir sobre quem será o vencedor com base nas peças de valores positivos altos ou de valores negativos que cada jogador obteve.

2. Ao final da partida, soma todas as peças de valor positivo. Posteriormente todas as de valor negativo; e, finalmente, diminui o valor de negativos do valor de positivos. Pode também somar todos os positivos e ir diminuindo esse valor de cada peça negativa, uma a uma.

3. No momento de contagem de pontos, efetua a operação com todas as peças juntas, considerando os negativos enquanto tais.

4. Mesmo utilizando procedimentos mais complexos, de níveis posteriores, erra a operação algébrica com as peças.

5. Contagem dos pontos com os dedos, em voz alta ou movendo os lábios.

6. Solicita papel e lápis para contagem dos pontos no final da partida.

7. Solicita ajuda do oponente para contagem ou para esclarecimento sobre como proceder com os números negativos no momento da contagem de pontos.

8. Utiliza função calculadora do celular como recurso para contar os pontos.

Nível IIB

1. Pergunta sobre a quantidade total de pontos da soma das peças do tabuleiro e quando todas são retiradas consegue inferir se ganhou ou perdeu. Porém, quando o jogo termina e sobram algumas peças no tabuleiro, não consegue fazer a operação dos valores das peças restantes sobre o total de pontos de todas as peças e saber qual o resultado da soma de suas peças e do adversário.

Nível III

1. Conta os seus pontos e os do adversário durante a partida, mesmo que apenas no início dela.

2. Sabe o número total de pontos da soma de todas as peças e quando sobram algumas ao final do jogo sobre o tabuleiro, consegue fazer a operação desse valor sobre o valor total das peças, sabendo qual será o resultado da soma de seus pontos e os do adversário.

3. Percebe se o oponente ou se ele mesmo contou incorretamente o número de pontos ao final da partida.

4. Na contagem de pontos ao término da partida, elimina positivos e negativos de mesmo valor (soma-zero) e faz operações somente com os números restantes.

5. Soma separadamente os positivos e os negativos, porém agrupa os números iguais em filas, fazendo operações parciais de multiplicação para efetuar as somas finais. Uma variação desse procedimento é o agrupamento de números em filas que somem 10 pontos. Depois, o participante efetua a multiplicação do número de filas por 10 para saber quantos pontos fez.

O resultado de pontos que cada jogador obteve na partida foi analisado em função do valor que ele verbalizou ao final de cada partida, após a contagem de pontos, e do valor real, contado pela pesquisadora a partir da análise das filmagens com as gravações das partidas. A comparação entre esses dois resultados possibilitou saber se o participante contou corretamente ou incorretamente os pontos ao final de cada partida.

\section{Resultados e Discussão}

Inicialmente, apresentaremos considerações sobre a contagem de pontos correta ou incorreta que os participantes realizaram ao final das seis partidas do jogo Mattix. Ao observarmos o desempenho do grupo de participantes na contagem de pontos, percebemos que em todas as partidas, na maioria das vezes, eles se equivocaram. Nenhum dos participantes contou corretamente os pontos em todas as seis partidas de que participou. Não observamos também ao longo das partidas uma diminuição sistemática no número de vezes em que os alunos contaram incorretamente (24 vezes na primeira partida, 22 na segunda, 20 na terceira, 22 na quarta, 20 na quinta e 27 na última). As menores proporções médias de contagem incorreta ocorreram nas Partidas 3 e 5 (0,59 nas duas).

Ao contarem os pontos no final da partida, os alunos do $7^{\circ}$ ano o fizeram incorretamente em $73 \%$ das vezes, enquanto que os alunos do $9^{\circ}$ ano contaram incorretamente em $63 \%$ das vezes. Entre os alunos do $7^{\circ}$ ano, três contaram incorretamente os pontos em todas as partidas que jogaram e, entre os alunos da $9^{\circ}$ ano, dois.

Vemos assim que em um grande número de vezes os alunos de ambas as séries não contaram corretamente os pontos. A nosso ver, não ocorreram situações em que os alu- 
Figura 2. Proporção dos níveis de procedimento de contagem de pontos utilizados pelos participantes nas seis partidas

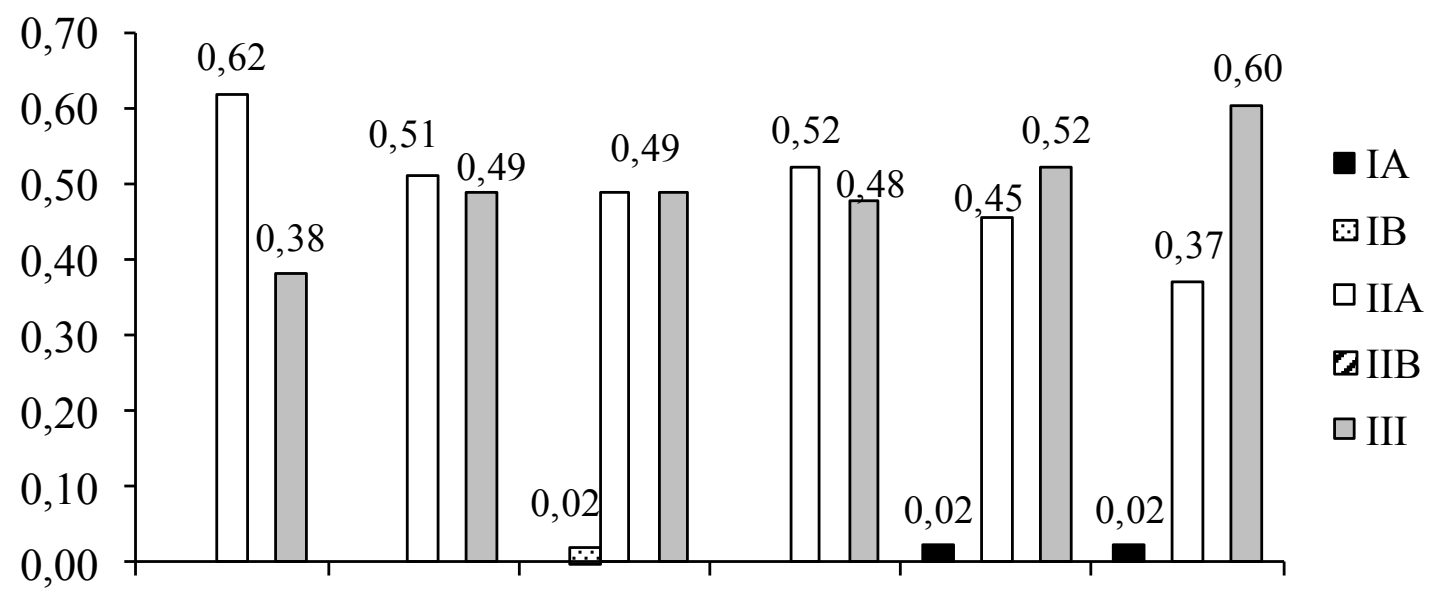

Partida 1 Partida 2 Partida 3 Partida 4 Partida 5 Partida 6

nos trapacearam relatando resultados incorretos com intuito de vencer o adversário, nem mesmo informaram valores ao acaso, sem a devida contagem das peças. Assim, esses percentuais indicam que eles não realizaram corretamente as operações matemáticas com as peças que obtiveram ao longo da partida.

Realizamos comparação entre as proporções de acerto e erro da contagem de pontos ao final de cada partida entre os sexos e entre as séries, por meio do Teste Binomial. Para essas comparações, não obtivemos diferenças estatisticamente significantes. Na comparação entre sexos, obteve-se para contagem correta $p$ valor=0,130 e, para incorreta, $p$ valor $=0,731$. Comparando-se as séries, obtivemos para contagem correta $p$ valor $=0,130$ e, para incorreta, $p$ valor $=0,863$.

Assim, os alunos contaram incorretamente na maioria das vezes, independente do sexo ou da série. Esse resultado corrobora com os resultados do SAEB 2003 (Klein, 2006), os quais mostram que a maioria dos alunos brasileiros possuiu desempenho em matemática abaixo do satisfatório. Apesar de os alunos da escola pesquisada encontrarem-se em posição privilegiada em comparação à população brasileira nos resultados dessa avaliação, tal vantagem não se mostrou positiva provavelmente em decorrência do desempenho da população ser muito baixo.

A maioria dos participantes utilizou mais de um procedimento, às vezes de complexidade diferente, para contagem dos pontos em cada partida. Esses procedimentos foram classificados em níveis, conforme apresentado anteriormente. A Figura $2 \mathrm{com}$ as proporções dos níveis de procedimento de contagem de pontos utilizados em cada partida encontra-se a seguir.

Os níveis IIA e III foram os mais utilizados pelos participantes. Percebemos que a proporção de procedimentos de nível III aumentou durante as partidas, superando a pro- porção de nível IIA nas duas últimas, demonstrando níveis mais complexos das estratégias utilizadas pelos alunos no decorrer da pesquisa. Entre os participantes, seis não apresentaram, em nenhuma das partidas, procedimentos de contagem do nível III. Desses, apenas um era do $9^{\circ}$ ano.

Para melhor caracterizar o desempenho da amostra, apresentamos a Tabela $1 \mathrm{com}$ as frequências de todas as características dos níveis de procedimento de contagem de pontos utilizados pelos jogadores.

A característica mais frequente foi a IIA.5, na qual os participantes contavam com os dedos, em voz alta ou movendo os lábios, ou seja, na qual recorriam a auxílios concretos para realizar as operações, não realizando o cálculo mental. A solicitação de papel e lápis (IIA.6) e a utilização da calculadora do celular (IIA.8) aconteceram apenas uma vez.

Em 19 vezes os participantes solicitaram a ajuda do oponente no momento de contagem (IIA.7), entretanto em apenas duas vezes solicitaram que o outro contasse para si (IA.1).

Também em uma única vez, uma participante do $7^{\circ}$ ano contou todas as peças como se fossem positivas (IB.1). O intrigante é o aparecimento desse dado apenas na Partida 3. Portanto, não foi por desconhecimento que essa participante contou dessa forma, já que não a utilizou nas demais. Além disso, ela perdeu a partida em questão.

Contar os números negativos como se fossem positivos não pode ser tomado como explicação para na maioria das vezes os participantes errarem a contagem dos pontos, pois esse procedimento só apareceu uma vez. Assim, não é por ignorar a diferença entre números positivos e negativos que esses alunos não conseguem realizar as operações.

Em 18 vezes os alunos contaram os pontos durante uma parte ou durante toda a partida (III.1), havendo uma das participantes do $9^{\circ}$ ano utilizado esse procedimento em todas as partidas. Apesar de usar esse procedimento de nível 
Tabela 1. Frequência de características de cada nível de procedimento de contagem de pontos nas seis partidas.

\begin{tabular}{ccccccc}
\hline Característica & Partida 1 & Partida 2 & Partida 3 & Partida 4 & Partida 5 & Partida 6 \\
\hline IA.1 & 0 & 0 & 0 & 0 & 1 & 1 \\
IB.1 & 0 & 0 & 1 & 0 & 0 & 0 \\
IIA.1 & 0 & 0 & 0 & 1 & 0 & 0 \\
IIA.2 & 17 & 14 & 10 & 14 & 11 & 8 \\
IIA.4 & 0 & 0 & 1 & 0 & 0 & 0 \\
IIA.5 & 18 & 17 & 18 & 17 & 12 & 15 \\
IIA.6 & 4 & 5 & 3 & 2 & 1 & 0 \\
IIA.7 & 6 & 3 & 1 & 3 & 5 & 1 \\
IIA.8 & 0 & 0 & 1 & 0 & 0 & 0 \\
III.1 & 1 & 1 & 5 & 2 & 4 & 5 \\
III.4 & 7 & 12 & 10 & 14 & 15 & 19 \\
III.5 & 10 & 9 & 13 & 12 & 14 & 15 \\
\hline
\end{tabular}

mais avançado, essa aluna contou incorretamente os seus pontos em cinco partidas.

Contar os pontos durante a partida é útil porque possibilita, a cada jogada, realizar planejamentos mais precisos sobre o número de pontos necessário para ampliar a vantagem ou reduzir a desvantagem em relação ao adversário.

No momento da contagem, em 70 vezes, os participantes realizaram operações algébricas separadamente com os números positivos e negativos para depois, com os resultados parciais, realizarem a operação que lhes daria o seu total de pontos (IIA.2). Em 77 vezes, os participantes utilizaram o procedimento que denominamos soma-zero (III.4) e, em 73 vezes, agruparam as peças iguais realizando multiplicações ou agruparam-nas de 10 em 10 pontos para facilitar a contagem de pontos (III.5).

É perceptível por meio desses procedimentos que os alunos diferenciavam números positivos e negativos, apesar de isso não se traduzir em contagem correta.

Em resolução oral de problemas de adição e subtração com números naturais de no máximo dois dígitos, Correa e Moura (1997) observaram dois procedimentos similares aos encontrados nesta pesquisa: a contagem com os dedos e a variação de resultados que, em nosso caso, apareceu quando os alunos realizaram agrupamentos de 10 em $10 \mathrm{com}$ os valores das peças ou quando realizaram agrupamentos com peças de mesmos valores.

Para essas autoras, o uso das estratégias que encontraram em sua pesquisa evidenciaram o conceito de "teorema em ação" de Vergnaud. Os dados aqui apresentados permitem-nos chegar à conclusão similar, já que muitos dos procedimentos adotados não faziam parte dos ensinamentos escolares, mas eram produções inventivas próprias dos alunos, mostrando que existem saberes para além do ambiente e das normas escolares (Correa \& Moura, 1997; Correia \& Meira, 1997; Panizza, 2006; Piaget, 1948/2005; Vergnaud 1990).

O procedimento de contagem de pontos nas partidas também foi analisado verificando associação com o sexo, com a série e com a contagem correta ou incorreta dos pontos ao final da partida. Quando um participante apresentou, em uma mesma partida, procedimentos de níveis diferentes, utilizamos, para possibilitar a análise estatística, apenas o nível mais alto apresentado por ele. Ao classificarmos, em cada partida, os procedimentos dessa forma, a maioria distribuiu-se entre os níveis IIA e III, com apenas um participante, em uma partida, no nível IA. Para permitir a análise estatística inferencial, eliminamos esse dado na análise. Perdemos também outros seis dados por contratempos ocorridos durante as filmagens das partidas.

A associação com sexo e com série foi verificada por meio do Teste Binomial. Com a variável sexo, não ocorreu associação estatística significativa nem para o nível IIA ( $p$ valor= 1) e nem para o nível III ( $p$ valor= 0,592).

Com a variável série, percebemos que, para os dois níveis de contagem de pontos analisados, temos associações significativas com a série do participante. O nível IIA, geralmente representado pelas características recorrer a auxílios concretos (dedos, falar em voz alta, papel) para realização dos cálculos ou contar positivos e negativos separadamente e depois realizar a operação algébrica com os dois valores, esteve mais presente entre os alunos do $7^{\circ}$ ano ( $p$ valor $=0,003$ ). Enquanto o nível III, representado principalmente pelas características efetuar a contagem pelo procedimento soma-zero ou realizar agrupamentos de números 
iguais e multiplicá-los ou agrupamentos de 10 em 10, teve maior proporção para os alunos do $9^{\circ}$ ano ( $p$ valor=0,002).

Esses resultados de associação entre procedimentos de contagem de pontos e série parecem ser dependentes de períodos de desenvolvimento (Piaget, 1964/2004; $1970 / 2002)$. Se os alunos do $7^{\circ}$ ano estão no período das operações concretas, como é plausível supor, é explicável o auxílio que buscam em procedimentos concretos (dedos, voz alta, papel) para auxiliar as operações de contagem. Entretanto, os alunos do $9^{\circ}$ ano, supostamente no início do período das operações formais, conseguiram criar procedimentos mais elaborados envolvendo abstração para contar seus pontos.

A associação entre o procedimento de contagem de pontos e contar corretamente ou incorretamente os pontos foi verificada por meio do Teste Qui-quadrado. Os resultados mostraram que a associação foi estatisticamente significante $(p$ valor $=0,0007)$, porém fraca $(V$ de Cramer= 0,24). Os coeficientes do resíduo estandardizado indicaram associações entre a utilização de características IIA para contagem de pontos e a contagem incorreta, e a utilização de características III e a contagem correta. Logo, um procedimento mais complexo de contagem de pontos (nível III) favoreceu a contagem correta dos pontos. Parece-nos importante, portanto, que educadores e psicólogos trabalhem não somente com a dimensão de acerto em determinado problema, mas que favoreçam a construção pelos alunos de procedimentos mais organizados e reflexivos para alcançarem as soluções corretas desses problemas. Assim, também se ressalta o papel ativo do sujeito, dando realmente condições para desenvolvimento de conhecimentos (Piaget, 1967/1996; Piaget \& Gréco, 1959/ 1974).

Apesar da associação entre procedimento mais alto de contagem de pontos III com o $9^{\circ}$ ano e com ter contado corretamente os pontos, é necessário lembrar que não ocorreram diferenças estatisticamente significativas para contagem correta e incorreta de pontos entre alunos do $7^{\circ} \mathrm{e}$ $9^{\circ}$ anos, conforme já apresentado.

\section{Conclusão}

A análise da contagem correta e incorreta dos pontos nos permite reforçar a preocupação demonstrada pelos dados alarmantes de Klein (2006) ao discutir a educação brasileira, pois mostra que a maioria dos alunos participantes da pesquisa não obteve êxito na realização de operações algébricas simples envolvendo números inteiros.

Entretanto, se não considerarmos apenas o resultado final, mas também o processo de alcance desse resultado, ou seja, os procedimentos utilizados para realização da contagem, é possível contribuir de forma mais significativa para a construção do conhecimento requisitado na operação com números inteiros. Pudemos constatar uma gama de procedimentos diferentes, nos quais os alunos mostraram seu papel de sujeito ativo em sua elaboração, pois utilizavam algumas estratégias que não são transmitidas na escola, mas inven- tadas por eles mesmos para atender a resolução de uma situação nova que Ihes era colocada pelo jogo, apesar de a escola poder funcionar como ambiente favorecedor - por meio de desafios, de interações com outras pessoas - para essa invenção.

Também buscando uma hipótese para esses resultados finais incorretos na soma das partidas, apoiando-nos nos procedimentos de contagem de pontos, é possível constatar que não é a ausência de reconhecimento da diferença entre números positivos e negativos que determina a contagem incorreta, pois, em apenas uma vez, o procedimento de contar todos os números como positivos foi apresentado. Entretanto, de acordo com a afirmativa de Vergnaud (1990) de que um conceito possui sentido a partir de situações e problemas a serem resolvidos, devemos formular uma consideração: muitas vezes, na escola, um conceito é formulado em termos linguísticos sem aplicação cotidiana pelos alunos, ou seja, teorema sem ação. Assim também acontece com os números inteiros, muitas vezes ensinados por premissas e regras. Entretanto, ao serem solicitados a conceituar, articulando esse conhecimento a uma aplicação a uma situação-problema a ser jogada (jogo Mattix), os indivíduos permanecem no campo das formulações verbais e não nos "campos conceituais". Logo, ao terem que operar com os números inteiros, aparecem dificuldades provenientes dessa incompreensão em ação.

Essa hipótese, investigada em futura pesquisa, poderia comprovar, ou lançar outras hipóteses sobre alguns dos resultados encontrados neste trabalho. No entanto, apesar de não ser essa a nossa crença, os resultados também podem ser explicados por uma dificuldade global em contar, independente do conjunto números naturais ou números inteiros. Outra hipótese que mereceria investigação.

A partir de todas nossas reflexões, consideramos também que, caso profissionais da educação tenham oportunidade de acompanhar não somente os resultados finais de seus alunos, mas todo o processo de elaboração de um conhecimento, serão capazes de contribuir de forma mais significativa para o processo de escolarização. E nessa área os jogos se mostram excelentes instrumentos para intervenção, já que possibilitam de forma prazerosa e ativa a construção do conhecimento pelo aluno e acompanhamento desse processo pelo professor.

\section{Referências}

Boyer, C. B. (2001). História da matemática (E. F. Gomide, trad.). São Paulo: Edgard Blücher.

Correa, J., \& Moura, M. L. S. de. (1997). A solução de problemas de adição e subtração por cálculo mental. Psicologia: Reflexão e Crítica, 10(1), 71-86.

Correia, M., \& Meira, L. (1997). Aemergência de objetivos matemáticos em um jogo de dominós. Psicologia: Teoria e Pesquisa, 13(3), 279-2. 
Dal Monte, L. N. (2006). Acerto de contas: dois duelos numéricos que exigem habilidade nos cálculos mentais. Superinteressante. Online. Recuperado: 10 mai. 2012. Disponível: http://super.abril. com.br/jogos/acerto_de_contas.html

Fainguelernt, E. K., \& Gottlieb, F. C. (2001). O jogo como metodologia no ensino de matemática. Teoria e Prática da Educação, 4(8), 141149.

Fisher, I. (2003). Algebra Games. Mathematics in school, 33(2), 2325.

Fisher, I. (2004). Negative Numbers. Mathematics in school, 33(3), 17-20.

French, D. (2001). Two minuses make a plus. Mathematics in school, 30(4), 32-33.

Instituto Nacional de Estudos e Pesquisas Educacionais Anísio Teixeira. (2008). Prova Brasil 2007: avaliação do rendimento escolar. On-line. Recuperado: 10 mai. 2012. Disponível: http:// provabrasil.inep.gov.br/

Klein, R. (2006). Como está a educação no Brasil? O que fazer? Ensaio: avaliação e políticas públicas em Educação, 14(51), 139172.

Marangon, C. (2004). Um jogo para treinar o cálculo mental. Nova Escola, 177,_58-59.

Ministério da Educação/ Secretaria de Educação Fundamental. (1998). Parâmetros curriculares nacionais: Matemática. Brasília: MEC.
Nieto, S. dos S. (1994). Antecipação do ensino dos números inteiros negativos para a quarta série do primeiro grau: um estudo das possibilidades. Dissertação de mestrado, Universidade Mackenzie, São Paulo.

Panizza, M. (2006). Reflexões gerais sobre o ensino da matemática. Em M. Panizza e cols, Ensinar matemática na educação infantil e nas séries iniciais. Porto Alegre, ArtMed.

Piaget, J. (2005). Para onde vai a educação? (I. Braga, trad.). Rio de Janeiro: José Olympio. (Trabalho original publicado em 1948)

Piaget, J. (2004). Seis estudos de Psicologia. Rio de Janeiro: Forense Universitária. (Trabalho original publicado em 1964)

Piaget, J. (1996). Biologia e Conhecimento. Petrópolis, RJ: Vozes. (Trabalho original publicado em 1967)

Piaget, J., \& Greco, P. (1974). Aprendizagem e Conhecimento (Equipe da Livraria Freitas Bastos, trad.) Rio de Janeiro: Freitas Bastos. (Trabalho original publicado em 1959)

Puritz, C. W. (2004). Using patterns with negative numbers or do two minuses really make a plus? Mathematics in school, 33(4), 26-27.

Tancredi, R. M. S. P. (1989). O ensino dos números inteiros no $1^{\circ}$ grau: realidade e posibilidades. Dissertação de mestrado, Universidade Federal de São Carlos, São Carlos, São Paulo.

Vergnaud, G. (1990). La théorie des champs conceptuels. Recherches en Didáctique des Mathématiques, 10(23), 133-170.

\section{Sobre os autores}

Cláudia Patrocinio Pedroza Canal (claudiapedroza@uol.com.br)

Professora do curso de Psicologia da IESFAVI; doutora em Psicologia pelo Programa de Pós-Graduação em Psicologia da Universidade Federal do Espírito Santo. Endereço: Travessa Araras - 269 - Jardim Marilândia - Vila Velha - ES - CEP 29 112-045

Sávio Silveira de Queiroz (savioqueiroz@terra.com.br)

Professor Associado do Departamento de Psicologia Social e do Desenvolvimento e do Programa de Pós-Graduação em Psicologia da Universidade Federal do Espírito Santo; doutor em Psicologia pelo Programa de Pós-Graduação em Psicologia Escolar e do Desenvolvimento Humano do Instituto de Psicologia da Universidade de São Paulo. Endereço: Rua Constante Sodré, 1077 - apt 803 - Praia do Canto - Vitória - ES - CEP 29055-420.

Artigo produto da tese de doutorado da primeira autora, sob orientação do segundo autor. A tese foi defendida em 2008 no Programa de PósGraduação em Psicologia da Universidade Federal do Espírito Santo. Agradecemos à instituição pública de Ensino Fundamental que permitiu a coleta de dados e à CAPES pela concessão de bolsa de doutorado. 